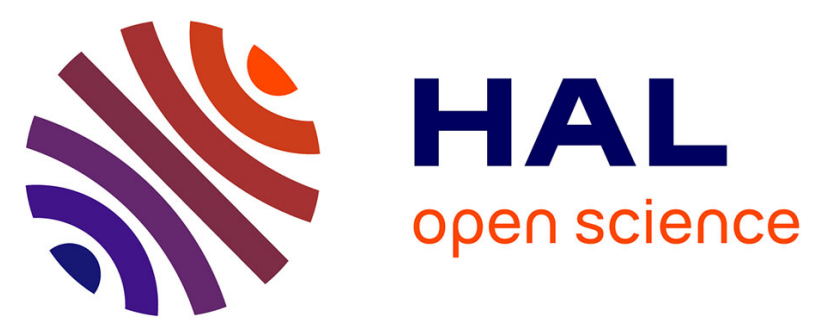

\title{
Differences in hypothalamic-pituitary-adrenal axis functioning among children with ADHD predominantly inattentive and combined types
}

Dirk West, Stephan Claes, Dirk Deboutte

\section{- To cite this version:}

Dirk West, Stephan Claes, Dirk Deboutte. Differences in hypothalamic-pituitary-adrenal axis functioning among children with ADHD predominantly inattentive and combined types. European Child and Adolescent Psychiatry, 2009, 18 (9), pp.543-553. 10.1007/s00787-009-0011-1 . hal-00535141

HAL Id: hal-00535141

https://hal.science/hal-00535141

Submitted on 11 Nov 2010

HAL is a multi-disciplinary open access archive for the deposit and dissemination of scientific research documents, whether they are published or not. The documents may come from teaching and research institutions in France or abroad, or from public or private research centers.
L'archive ouverte pluridisciplinaire HAL, est destinée au dépôt et à la diffusion de documents scientifiques de niveau recherche, publiés ou non, émanant des établissements d'enseignement et de recherche français ou étrangers, des laboratoires publics ou privés. 


\title{
Differences in hypothalamic-pituitary-adrenal axis functioning among children with ADHD predominantly inattentive and combined types
}

\author{
Dirk van West $\cdot$ Stephan Claes $\cdot$ Dirk Deboutte
}

Received: 24 November 2008/ Accepted: 26 February 2009/Published online: 18 March 2009

(C) Springer-Verlag 2009

\begin{abstract}
Some evidence suggests that the HPA axis may be dysfunctional in children with attention-deficit/hyperactivity disorder (ADHD). The aim of this study was to investigate whether a different pattern of HPA axis activity is found between the inattentive (I) and combined (C) subtypes of ADHD, in comparison with healthy control children. A total of 100 prepubertal subjects [52 children with ADHD combined type (ADHD-C), 23 children with ADHD predominantly inattentive type (ADHD-I), and 25 healthy control subjects] were studied. The effects of stress were studied by comparing cortisol responses to a psychosocial stressor, consisting of a public speaking task. Children with ADHD-I showed an elevated cortisol response to the psychosocial stressor, in contrast to children with ADHD-C who showed a blunted cortisol response to the psychosocial stressor. When a distinction was made between responders and non-responders (a subject was classified as a responder when there was an increase in cortisol reactivity), hyperactivity symptoms were clearly related to a lower cortisol reactivity to stress. The results indicate that a low-cortisol responsivity to stress may be a neurobiological marker for children with
\end{abstract}

D. van West $(\bowtie) \cdot$ D. Deboutte

University Center of Child and Adolescent Psychiatry Antwerp

(UCKJA), ZNA Middelheim, University of Antwerp,

Lindendreef 1, 2020 Antwerp, Belgium

e-mail: dirk.vanwest@zna.be

S. Claes

University Psychiatric Center, Campus Leuven,

University of Leuven, Herestraat 49, 3000 Leuven, Belgium

D. van West $\cdot$ S. Claes $\cdot$ D. Deboutte

The Collaborative Antwerp Psychiatric Research Institute (CAPRI), University of Antwerp, Universiteitsplein 1,

2610 Wilrijk, Belgium
ADHD-C, but not for those with ADHD-I. Directions for future research and clinical implications are discussed.

Keywords ADHD - Children - Cortisol - HPA axis . Stress

\section{Introduction}

Attention-deficit/hyperactivity disorder (ADHD) is a neurodevelopmental disorder that begins early in childhood and is characterized by three main symptoms: inattention, hyperactivity, and impulsivity. The prevalence of ADHD in school-aged children is approximately $3-7 \%$ [4]. Although the rate of ADHD declines with age, at least half the children with the disorder will exhibit symptoms in adulthood [8]. ADHD is accompanied by academic underachievement, substance abuse, conduct problems, anxiety, depression, marital problems, and occupational adjustment $[9,10]$.

According to Gray's motivational theory [23-26] three interdependent brain systems govern behavior: the fight/ flight system, the reward or behavioral activation system (BAS) and the behavioral inhibition system (BIS). The BAS and BIS have opposite effects relative to each other; an imbalance in BIS/BAS levels can result in the emergence of psychopathology. When BAS functioning has the upper hand, either approach or active avoidance results. When BIS functioning predominates, passive avoidance is likely. Some theorists have argued that dysfunction of the BIS has major roles in the mechanism of ADHD $[6,51,56$, 60]. Dysfunction of the BIS results in secondary deficits of working memory, self regulation of affect, internalization of speech and reconstitution like goal-directed behavior [6]. Activation of the BIS results in endocrinological 
responses, including elevation of the level of cortisol [59]. If one of the core deficits of ADHD is the dysfunctional BIS, abnormality in hypothalamic-pituitary-adrenal (HPA) axis activity should be observed in patients with ADHD. An inference is also drawn from the clinical features that the HPA axis, which is involved in emotion, learning, and attention, may be impaired in children with ADHD.

Most studies in children with disruptive behavior disorders (DBD) have focused on oppositional defiant disorder (ODD) and conduct disorder (CD). However, both in clinical $[21,39,41]$ and in general population studies $[20,31,64,70]$, there is sufficient evidence to assume that ADHD and ODD/CD are independent disorders with different pathophysiology. It is therefore important to distinguish between disruptive children (i.e., those with ODD or CD), and children with ADHD alone when investigating HPA axis reactivity in children with externalizing behavior problems.

Up to now only a few researchers investigated the role of the HPA axis in clinical samples of children with ADHD. Kaneko et al. [32] examined HPA axis functioning in 30 children with ADHD by measuring the diurnal variation and response to the dexamethasone suppression test (DST). They found a normal diurnal salivary cortisol rhythm in only $43 \%$ of the ADHD children and DST suppression in $47 \%$ of the ADHD children. Moreover, a positive association was reported between hyperactivity and abnormal diurnal rhythm and nonsuppression to the DST [32]. Schulz et al. [63] found no inverse relationship between cortisol secretion and aggressive behavior in boys with ADHD. In a study of King et al. [35], the cortisol levels of patients with ADHD, who retained their diagnosis over the first year of the study, showed a blunted response to stress compared to those that no longer retained the disorder. They suggested that an impaired response to stress might be a marker for the more developmentally persistent form of the disorder. Kariyawasam et al. [33] found lower cortisol levels in 32 children with comorbid ADHD and ODD; this reduction was restricted to the subgroup of patients not prescribed stimulant medication. Hong et al. [29] investigated HPA axis functioning in children with ADHD after a computerized continuous performance test. They suggested that the blunted HPA axis response to stress was related to the impulsivity in children with ADHD.

Although previous studies reported that some patients with ADHD have dysfunctional HPA axis reactivity, no studies investigated the stress response after a psychosocial stress test. Moreover, small sample sizes and other methodological difficulties (e.g., no classification in subtypes) are a profound limitation in the previous studies which examined HPA axis functioning in ADHD children. Furthermore, these studies assumed that ADHD is neurobiologically homogeneous, not taking into account the various subtypes.

According to the Diagnostic and Statistical Manual of Mental Disorders (DSM-IV-TR) [4] ADHD can be divided into three subtypes: ADHD predominantly inattentive subtype (ADHD-I), ADHD predominantly hyperactive/ impulsive subtype (ADHD-H), and ADHD combined subtype (ADHD-C). The emphasis has shifted from a onedimensional conceptualization to a model consisting of two factors: hyperactivity/impulsiveness and inattention. In the current categorical clinical view, these three subtypes belong to the same diagnostic entity. However, some researchers claim that the inattentive subtype is a distinct disorder and not a subtype of ADHD [5, 7, 16, 48]. More specifically, the three subtypes are different from each other in inattention symptoms, associated features, demographics, and responsiveness to stimulant medication [13, $18,22,54]$. Nonetheless, the distinctiveness of the ADHD subtypes on neurobiological measures is not clear-cut. Therefore, the aim of the current study is to investigate HPA axis reactivity to a psychosocial stress test in prepubertal children with ADHD subtypes and in healthy control children. Our primary hypothesis was that children with ADHD-C would show cortisol hyporeactivity during psychosocial stress, relative to ADHD-I subjects and healthy control individuals.

\section{Methods}

Subjects

Seventy-five children, of age between 6 and 12 years, with ADHD, recruited from the psychiatric outpatient's clinic at the University Center of Child and Adolescent Psychiatry in Antwerp, were the subjects of this study. Parent ratings of behavior were ascertained using the Child Behavior Checklist (CBCL) [2]. Teacher ratings of behavior were obtained using the Teacher Report Form (TRF) [3]. In addition, the Kiddie-SADS-Present and Lifetime Version 1.0 with supplement (K-SADS-PL), a semistructured DSMIV based psychiatric interview, was administered to children and parents $[34,58]$. This semistructured interview has been used extensively to make diagnostic decisions based on DSM criteria and has been validated with children aged 6-17. The interview was first administered to the parent alone, who rates the child's symptoms (current and most severe past). The same clinician then administers the identical interview to the child alone, adjusted to the developmental level of the child. After the child interview, a third pair of ratings is made which represents the clinician's consensus of summary severity scores for each symptom on the basis of all available information (parent, child, school). 
When there were little discrepancies, the rater used his/her best clinical judgement. When there were major discrepancies in the child and parent reports, they were interviewed together to clarify their views. All subjects met DSM-IV criteria for ADHD based on psychological assessment and psychiatric interviews with the child, interviews with the parents including discussion of the child's developmental history, and the administration of parent and child responses to the K-SADS. Interviews and diagnoses were performed by trained child and adolescent psychiatrists. When consensus was reached between two child psychiatrists ( DvW, DD) on the basis of information of the different informants, the individuals were assigned to one of the diagnostic groups. Severity of symptoms was assessed with the ADHD rating scale (AVL) [62]. AVL is a questionnaire consisting of 18 items and three subscales: inattention, hyperactivity, and impulsivity. Behavioral symptoms were evaluated using a five-point Likert-type scale: $0=$ not; $1=$ occasionally (or incidentally); $2=$ regularly (or monthly); $3=$ often (or weekly); $4=$ very often (or daily) and was scored by the clinician. The total score is computed as the sum of the scores on each of the 18 items. In addition to the total score, the scores from the inattention, hyperactivity, and impulsivity subscales were computed. All subscales have good internal consistency (Cronbach's alpha $=0.89$ 0.93 ), inter-rater reliability (Kappa statistic $=0.83-0.92$ ), test-retest reliability (Intra-class correlation coefficient $=$ $0.92-0.95$ ), and construct and discriminant validity. Fiftytwo children met criteria for the ADHD-C subtype and 23 children met criteria for the ADHD-I subtype. No child met diagnostic criteria for the ADHD-H subtype. Although there is a high rate of comorbid disorders among patients with ADHD, all patients with a comorbid diagnosis in addition to ADHD were excluded to achieve a more homogenous sample. Comorbid symptomatology was described from a dimensional point of view using CBCL and TRF scores. However, ten (19\%) children with the ADHD-C subtype had a learning disability (10\% reading and $15 \%$ math disability) compared to 7 (26\%) children with the ADHD-I subtype (13\% reading and 22\% math disability). None of the ADHD subjects or healthy controls was on medication.

Twenty-five control subjects 6-12 years old were recruited from grades 1 to 6 of regular local elementary schools and screened for psychiatric problems, using the CBCL filled out by the parents. None of the children had any symptom cluster score above the 98th percentile and none had a CBCL attention problem score above the 84th percentile.

All children with a Full-Scale IQ, as measured by the Wechsler Intelligence Scale for Children-Revised (WISCR) [72] of less than 85 and children with a history of any neurologic or endocrinologic disorder were excluded from this study. All children were physically well on the day of testing, and none of them had signs of current infection. None of the children had recent tooth loss and children were asked to refrain from eating and drinking for at least $1 \mathrm{~h}$ before the beginning of the test session (since blood or food in saliva are known to alter cortisol values).

Stage of pubertal development was assessed in the parent interview using schematic drawings of secondary sex characteristics associated with the five standard Tanner stages of pubertal development (score range: 1-5) [43]. Subjects with a score higher than 2 were excluded from the study. As a second measure of physical development, the body mass index (BMI) was computed. Socioeconomic status (SES) was measured using the Hollingshead FourFactor Index of Social Status [28]. This measure generates an SES score for each family based upon maternal and paternal education and occupation. Pubertal development [27, 47], SES [42] and body composition [71] are all associated with various kinds of psychopathology, which makes them candidate confounders provided they are also related to individual differences in the cortisol measures.

The study was approved by the Medical Ethical Committee of the University of Antwerp, and parents gave written informed consent after investigators explained the purpose and course of the study.

\section{Study design}

The psychosocial stress test consisted of a public speaking task (PST); it is well demonstrated that this stressor is effective in both children and adults [17, 38]. The PST was imbedded in a 135-min test session, consisting of an initial resting period $(60 \mathrm{~min})$, the PST $(15 \mathrm{~min})$ and a post-test resting period (60 min) (Fig. 1). For this population, we used an adapted version of the Trier Social Stress Test (TSTT) [36], mainly by shortening its duration and increasing its relevance to participants. This procedure has been described in detail elsewhere [69]. For each subject, seven saliva samples were collected for measurement of the cortisol concentration. The first saliva sample was taken during the initial resting period, $30 \mathrm{~min}$ after the start of the test session $(t=-30)$. The second sample was taken after $60 \mathrm{~min}$, at the end of the initial rest period just before the public speaking task $(t=0)$. Saliva was also collected right after the 10-min preparation period $(t=10)$ and after the 5-min talk $(t=15)$. During the second rest period of an hour, a further three saliva samples were collected at 20-min intervals $(t=35,55,75)$ (Fig. 1).

Saliva assay

All stress tests were carried out in the afternoon, when the HPA-activity is low and stable and therefore more 


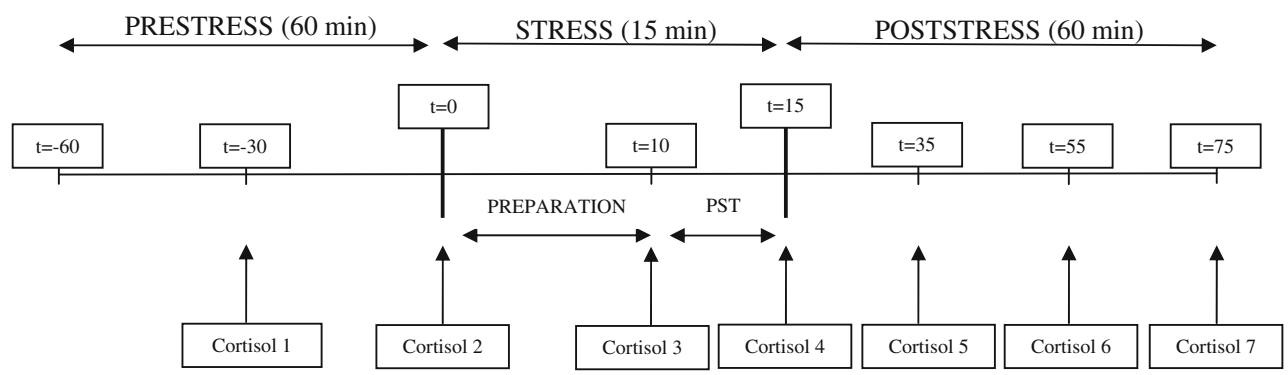

Fig. 1 Study design

susceptible to stimulation [37]. Cortisol can be measured from saliva in a reliable and stress-free way [37], and reflects the biologically active (unbound) fraction of serum cortisol [1]. After the start of an effective stressor, salivary cortisol increases can be observed 15-20 min later [37]. Subjects collected saliva by holding a dental roll in the mouth and chewing on for 30-90 s until they felt that the swab was soaked with saliva. The saturated roll was placed in Salivette (Sarstedt, Nümbrecht, Germany) collection devices and stored at room temperature until completion of the session. Samples were then stored at $-20^{\circ} \mathrm{C}$ until biochemical analysis. Salivettes were centrifuged at 3,000 rpm for $5 \mathrm{~min}$, which resulted in a clear supernatant of low viscosity. Cortisol analyses were performed in duplicate by direct radio-immunoassay on $100 \mu \mathrm{l}$ of salivary free cortisol samples in competition, with a HPLC preparation of cortisol-3CMO coupled with 2-[125I]odohistamine as tracer, for specific antibodies raised against cortisol-3-CMO-BSA [66]. The lower detection limit of the assay was $12 \mathrm{ng} / \mathrm{dl}$, with a mean intra-assay coefficient of variation of $4.3 \%(n=10)$. The coefficients of variation for between-run assays are 12.26 and $9.38 \%$ (at concentrations of $34.39 \pm 4.22$ and $410.59 \pm 38.53 \mathrm{ng} / \mathrm{dl}$, respectively) $(n=30)$. Each sample was processed in duplicate.

\section{Statistics}

Because cortisol values were positively skewed, they were transformed to the natural logarithm scale to render the distributions more symmetrical and normally distributed as tested with a Kolmogorov-Smirnov analysis. All other variables were normally distributed. Differences in gender ratio between groups were tested by using chi-square analysis. One-factor analyses of variance (ANOVAs) were used to assess the effect of diagnostic group on age, Tanner stage, BMI, SES, IQ, clinical symptom cluster scores (AVL, CBCL, TRF), and cortisol variables. Repeated-measures ANOVA with "group" (ADHD-I vs. ADHD-C vs. NC) as between-subjects factor and "time" as within-subjects factor were used to assess changes in levels of $\log$ (cortisol). Huynh-Feldt corrections were used where the assumption of sphericity was violated. Main effects of "time" and interactions between "time" and "group" were further analyzed by conducting difference contrast tests, i.e., comparing the values of a sample at a certain time point to all previous ones. All post hoc analyses were corrected with the Bonferroni method for multiple comparisons. As a specific measure of responsivity to the stressor, four additional cortisol variables were computed: basal, AUCtot, AUCnet, and Deltapeak. Basal represents the mean free cortisol concentration over the two time points before the PST. Deltapeak is the maximum free cortisol concentration after the PST corrected for basal. The area under the curve (AUC) was calculated to incorporate the cortisol concentrations at five time points after the initial resting period according to the trapezoid method described by Pruessner et al. [55]. AUCtot is the total area under the curve and represents the total cortisol output. AUCnet is identical to AUCtot, except for the removal of the area between the ground and Basal. When a negative value was the result for this measure, this would typically be set to zero to avoid a negative area measure and to denote the lack of an increase for this subject [55]. Because this results in a potential loss of information about the strength of the decrease, we continued the statistical analysis including negative values. The results were therefore "indices of decrease" rather than an area [55]. Relationships between psychometric scores and stress reactivity (AUC_net) were examined by using Pearson correlation coefficients. Finally, a logistic regression model was applied to the data to study the possible explanatory variables for change in cortisol. All tests were two-tailed and statistical significance was set at $P \leq 0.05$. Following Cohen's guidelines [15], $r$ values of $0.10,0.30$, and 0.50 (correlation), $f$ values of $0.10,0.25$, and 0.40 (ANOVA), and $f^{2}$ values of $0.02,0.15$, and 0.35 (Repeatedmeasures ANOVA) are generally used as thresholds to define small, medium, and large effects, respectively. For statistical analysis, we used SPSS for Windows, version 15.0 


\section{Results}

\section{Performance}

All children in the study managed to give a talk during the PST. The number of interruptions was not significant different between diagnostic groups: mean number of interruptions were $3.5 \pm 3.1$ for the ADHD-C subtype, $4.0 \pm 2.8$ for the ADHD-I subtype, and $2.7 \pm 2.0$ for the group of control children. Performance on the PST was not correlated with the patient's IQ.

Demographic and psychometric characteristics

Demographic characteristics of ADHD children and healthy controls are shown in Table 1 . There was no significant difference between ADHD-C subtype versus ADHD-I subtype versus NC group status in any of the demographic variables. Table 2 shows ADHD symptom scores and $T$ scores of CBCL, and TRF. The ADHD-C subtype differed significantly from the ADHD-I subtype and normal controls in their mean AVL Total, hyperactivity, and impulsivity scores. Inattention scores were not different between the ADHD-C subtype and the ADHD-I subtype. Both groups of ADHD children (combined and predominantly inattentive type) differed significantly from the normal controls in all their mean CBCL and TRF scores (except TRF scores for somatic complaints and delinquency). The ADHD-C subtype had significantly higher scores compared to the ADHD-I subtype and the normal controls in their mean CBCL scores for social problems, delinquency, aggressive behavior, externalizing and total problem behavior and TRF scores for delinquency, aggressive behavior, and externalizing problem behavior. The ADHD-I subtype had significantly higher scores compared to the ADHD-C subtype and the normal controls in their mean CBCL scores for withdrawn and somatic complaints, and TRF scores for withdrawn and internalizing problem behavior. The ADHD and NC group could not be differentiated on the basis of their scores on the TRF somatic problems scale.

\section{Cortisol}

A graphic representation of mean salivary log (cortisol) levels by subgroup is shown in Fig. 2. Repeated-measures ANOVA revealed a significant main effect of time for salivary cortisol levels $[F=82.68, P<0.001$; effect size $\left.f^{2}=0.46\right]$. Difference contrasts revealed that this was mainly attributable to significant effects for samples 10 min after preparation period (sample 3 ) $[F=32.20$, $P<0.001]$, immediately (sample 4) $[F=84.59$, $P<0.001], 20 \mathrm{~min}$ (sample 5) $[F=57.43, P<0.001]$ and $60 \mathrm{~min}$ (sample 7 ) $[F=223.36, P<0.001]$ after the talk. Furthermore, a significant main effect of group $\left[F=14.54, P<0.001\right.$; effect size $\left.f^{2}=0.23\right]$ and a significant group by time interaction was found $[F=21.91$, $P<0.001$; effect size $\left.f^{2}=0.31\right]$. Difference contrast tests, comparing each sample with all previous ones, revealed that this was because of significant differences for samples $10 \mathrm{~min}$ after preparation period (sample 3 ) $[F=9.43$, $P<0.001]$, $20 \mathrm{~min}$ (sample 5) $[F=32.82, P<0.001]$, $40 \mathrm{~min}$ (sample 6) $[F=46.09, P<0.001]$ and $60 \mathrm{~min}$ (sample 7 ) $[F=17.78, P<0.001]$ after the talk.

Table 3 lists the four cortisol variables (basal, Deltapeak, AUCtot and AUCnet) with the standard deviations in all three samples. An ANOVA on HPA reactivity to the stressor, by subgroup (ADHD-I vs. ADHD-C vs. NC), revealed a significant difference between groups for basal $[F=3.28, P=0.04 ; f=0.06]$, deltapeak $[F=13.98$,

Table 1 Demographic characteristics of patients with ADHD, predominantly inattentive subtype (ADHD-I), combined subtype (ADHD-C) and healthy controls. Mean values and standard deviations

\begin{tabular}{|c|c|c|c|c|c|c|c|}
\hline \multirow[t]{2}{*}{ Measure } & \multicolumn{2}{|c|}{ ADHD-C $(n=52)$} & \multicolumn{2}{|c|}{ ADHD-I $(n=23)$} & \multicolumn{2}{|c|}{ Control $(n=25)$} & \multirow[t]{2}{*}{$F(2,97)$} \\
\hline & Mean & SD & Mean & SD & Mean & SD & \\
\hline Age & 8.52 & 1.84 & 8.65 & 1.47 & 8.88 & 1.54 & 0.39 \\
\hline Gender $(\mathrm{M} / \mathrm{F})$ & $45 / 7$ & & $18 / 5$ & & $20 / 5$ & & $\chi_{2,0.95}^{2}=0.99$ \\
\hline Tanner stage & 1.02 & 0.14 & 1.04 & 0.21 & 1.08 & 0.28 & 0.81 \\
\hline BMI & 16.29 & 2.05 & 16.57 & 2.00 & 16.48 & 1.77 & 0.18 \\
\hline SES & 39.92 & 7.14 & 43.30 & 7.59 & 42.40 & 5.66 & 2.31 \\
\hline TIQ & 99.67 & 8.14 & 101.24 & 10.97 & 103.86 & 10.80 & 0.86 \\
\hline VIQ & 100.40 & 9.72 & 101.04 & 9.87 & 103.62 & 13.69 & 0.53 \\
\hline PIQ & 98.93 & 7.65 & 101.78 & 9.42 & 102.81 & 10.00 & 1.05 \\
\hline
\end{tabular}

All test results were not significant

$B M I$ body mass index, $S E S$ socioeconomic status, $T I Q$ total intelligence quotient, $V I Q$ verbal intelligence quotient, $P I Q$ performance intelligence quotient 
Table 2 Psychometric characteristics in patients with ADHD, predominantly inattentive subtype (ADHD-I), combined subtype (ADHD-C) and healthy controls

\begin{tabular}{|c|c|c|c|c|c|c|}
\hline & & $\begin{array}{l}\text { ADHD-C } \\
(n=52)\end{array}$ & $\begin{array}{l}\text { ADHD-I } \\
(n=23)\end{array}$ & $\begin{array}{l}\text { Control } \\
(n=25)\end{array}$ & $F(2,97)$ & Contrasts $^{\mathrm{a}}$ \\
\hline \multirow[t]{4}{*}{ AVL } & Total & $46.2(12.4)$ & $23.7(7.2)$ & $9.7(5.4)$ & $121.8 * *$ & ADHD-C $>$ ADHD-I $>$ NC \\
\hline & Inattention & $16.9(4.3)$ & $15.7(4.1)$ & $3.3(2.2)$ & $110.4 * *$ & ADHD-C, ADHD-I > NC \\
\hline & Hyperactivity & $14.4(6.7)$ & $4.3(4.5)$ & $3.9(4.4)$ & $40.8 * *$ & ADHD-C > ADHD-I, NC \\
\hline & Impulsivity & $14.9(6.4)$ & $3.7(3.3)$ & $2.5(2.3)$ & $69.5 * *$ & ADHD-C > ADHD, NC \\
\hline \multirow[t]{11}{*}{ CBCL } & Withdrawn withdrawal & $61.3(6.6)$ & $65.5(4.3)$ & $50.9(2.3)$ & $50.8 * *$ & ADHD-I $>$ ADHD-C $>$ NC \\
\hline & Somatic complaints & $57.4(6.5)$ & $61.4(6.8)$ & $52.3(4.2)$ & $13.5^{* *}$ & ADHD-I $>$ ADHD-C $>$ NC \\
\hline & Anxious/depressed & $63.3(5.2)$ & $64.1(5.3)$ & $51.6(4.1)$ & $53.7 * *$ & ADHD-C, ADHD-I > NC \\
\hline & Social problems & $62.1(5.9)$ & $57.1(3.0)$ & $50.7(2.1)$ & $51.3 * *$ & ADHD-C $>$ ADHD-I $>$ NC \\
\hline & Thought problems & $60.8(8.5)$ & $59.9(7.3)$ & $50.4(2.0)$ & $18.9 * *$ & ADHD-C, ADHD-I > NC \\
\hline & Attention problems & $71.0(4.2)$ & $70.0(5.0)$ & $52.8(6.4)$ & $119.8^{* *}$ & ADHD-C, ADHD-I > NC \\
\hline & Delinquency & $63.4(1.8)$ & $56.1(6.4)$ & $51.4(3.7)$ & $91.5^{* *}$ & ADHD-C $>$ ADHD-I $>$ NC \\
\hline & Aggression & $64.0(2.8)$ & $55.6(5.6)$ & $51.5(4.5)$ & $91.3 * *$ & ADHD-C $>$ ADHD-I $>$ NC \\
\hline & Externalizing score & $64.2(2.0)$ & $53.9(6.0)$ & $45.0(8.7)$ & $113.2 * *$ & ADHD-C $>$ ADHD-I $>$ NC \\
\hline & Internalizing score & $61.9(4.0)$ & $63.5(2.2)$ & $47.6(7.3)$ & $92.5 * *$ & ADHD-C, ADHD-I > NC \\
\hline & Total problem score & $64.2(3.4)$ & $59.0(3.0)$ & $45.6(9.2)$ & $100.0 * *$ & ADHD-C $>$ ADHD-I $>$ NC \\
\hline \multirow[t]{11}{*}{ TRF } & Withdrawn & $56.8(8.4)$ & $61.8(6.2)$ & $51.2(2.9)$ & $14.1 * *$ & ADHD-I $>$ ADHD-C $>\mathrm{NC}$ \\
\hline & Somatic complaints & $54.3(6.3)$ & $52.3(4.4)$ & $51.6(4.0)$ & 2.5 & - \\
\hline & Anxious/depressed & $57.6(5.9)$ & $59.8(4.3)$ & $50.7(2.1)$ & $24.2 * *$ & ADHD-C, ADHD-I > NC \\
\hline & Social problems & $61.4(7.1)$ & $59.5(5.5)$ & $50.5(1.5)$ & $30.0 * *$ & ADHD-C, ADHD-I > NC \\
\hline & Thought problems & $56.2(8.1)$ & $55.5(7.9)$ & $50.3(1.2)$ & $6.4^{*}$ & ADHD-C, ADHD-I > NC \\
\hline & Attention problems & $65.0(3.7)$ & $64.0(4.0)$ & $50.6(1.8)$ & $160.4^{* *}$ & ADHD-C, ADHD-I > NC \\
\hline & Delinquency & $60.3(4.0)$ & $55.0(2.3)$ & $52.4(4.7)$ & $40.2 * *$ & ADHD-C > ADHD-I, NC \\
\hline & Aggression & $62.3(3.4)$ & $55.9(2.1)$ & $52.2(3.5)$ & $92.4 * *$ & ADHD-C $>$ ADHD-I $>$ NC \\
\hline & Externalizing score & $61.1(2.8)$ & $52.4(7.7)$ & $47.1(6.1)$ & $67.2 * *$ & ADHD-C $>$ ADHD-I $>$ NC \\
\hline & Internalizing score & $55.1(4.2)$ & $58.3(5.2)(5.28 .3)$ & $42.6(6.1)$ & $72.2 * *$ & ADHD-I $>$ ADHD-C $>$ NC \\
\hline & Total problem score & $60.9(4.4)$ & $59.3(3.0)$ & $42.5(7.1)$ & $122.4 * *$ & ADHD-C, ADHD-I > NC \\
\hline
\end{tabular}

Mean values and standard deviations

${ }^{\text {a }}$ Bonferroni, $P<0.05 ; * P<0.01 ; * * P<0.001$

$P<0.001 ; f=0.22]$, AUCtot $[F=24.52, P<0.001$, $f=0.34]$, and AUCnet $[F=36.40, P<0.001, f=0.44]$. Post hoc analysis showed significant differences between both the ADHD-I and control groups and the ADHD-C group on deltapeak $(P<0.001$ and $P<0.01$, respectively) and AUCtot (both $P<0.001$ ). Furthermore, the ADHD-I group had significantly higher AUCnet levels compared with the ADHD-C group $(P<0.001)$ and the control group $(P<0.01)$; the control group had significantly higher basal levels of cortisol compared with the ADHD-C group $(P=0.03)$.

CBCL scores for delinquency $(r=-0.48, P<0.001)$, aggressive behavior $(r=-0.43, P<0.001)$, externalization problems $(r=-0.24, P=0.02)$, and total problems ( $r=-0.26, P=0.008)$ were significantly and negatively correlated with AUC_net. CBCL, and TRF scores for social withdrawal $(r=0.31, P=0.002$ and $r=0.26$, $P=0.009$, respectively) were significantly and positively correlated with AUC_net. A trend for a negative correlation between TRF scores for Aggressive Behavior $(r=$ $-0.18, \quad P=0.07)$ and externalization problems $(r=$ $-0.19, P=0.06$ ), and AUC_net was also found. Moreover, hyperactivity $(r=-0.82, \quad P<0.001) \quad$ and impulsivity $(r=-0.82, P<0.001)$ scores were significantly and negatively correlated with AUC_net.

Finally, all subjects were divided into responders and non-responders in terms of the cortisol response to the psychosocial stress test in order to evaluate factors that may be responsible for response or non-response to the stressor. A subject was classified as a responder when there was an increase in cortisol reactivity (positive AUC_net value). By this criterion, 18 (35\%) of 52 ADHD-C patients, $22(96 \%)$ of 23 ADHD-I patients and $22(88 \%)$ of 25 control subjects, were qualified as cortisol responders. There was no significant difference between responders versus non-responders in any of the demographic variables. 
Fig. 2 Salivary cortisol responses to the psychosocial stress test in patients with ADHD, predominantly inattentive subtype (ADHD-I), combined subtype (ADHD-C) and healthy controls. Mean values and standard error scores are indicated

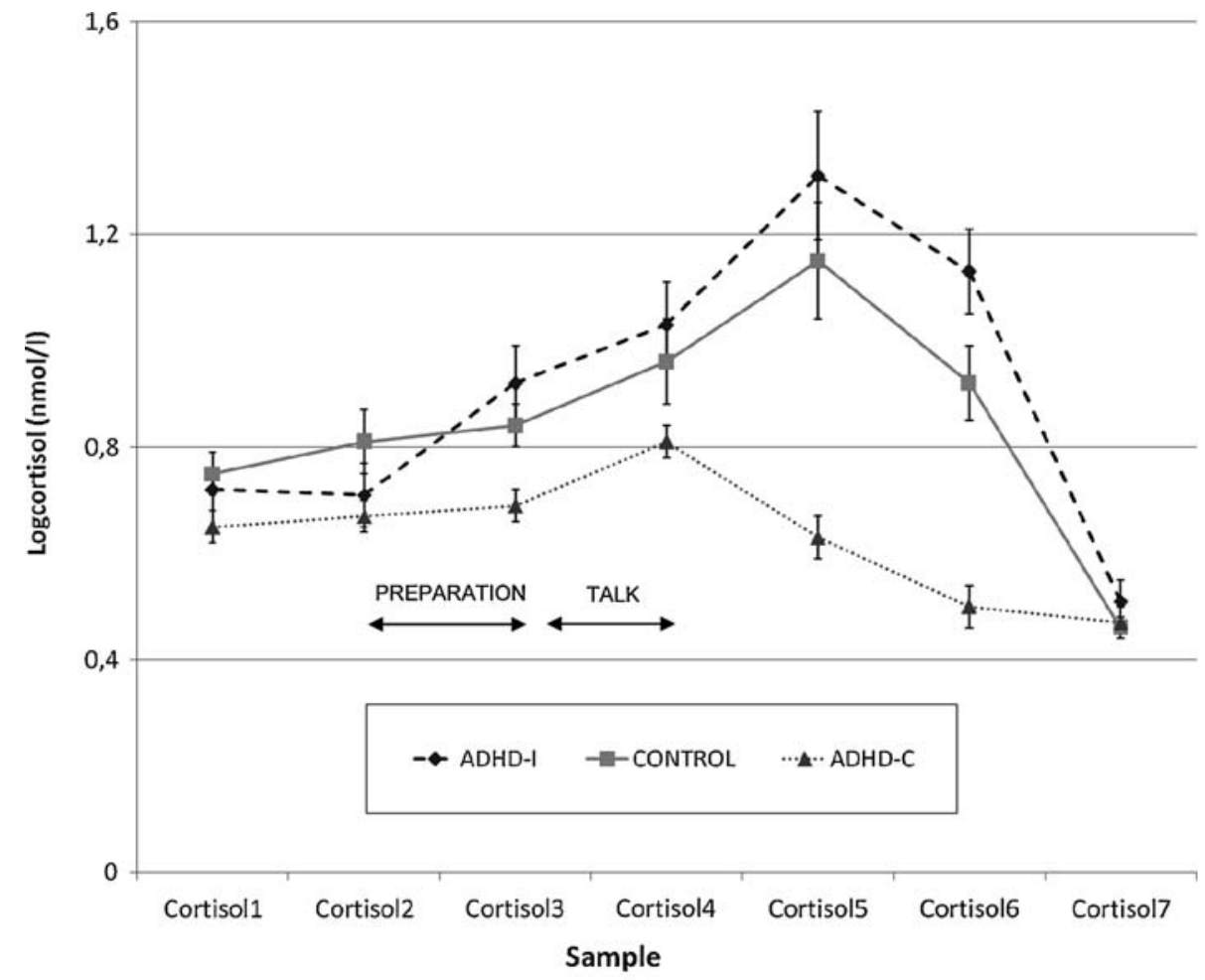

Table 3 Mean values of the four computed cortisol variables in patients with ADHD, predominantly inattentive subtype (ADHD-I), combined subtype (ADHD-C) and healthy controls

\begin{tabular}{|c|c|c|c|c|c|c|c|c|}
\hline \multirow[t]{2}{*}{ Measure } & \multicolumn{2}{|c|}{ ADHD-C $(n=52)$} & \multicolumn{2}{|c|}{ ADHD-I $(n=23)$} & \multicolumn{2}{|c|}{ Control $(n=25)$} & \multirow[t]{2}{*}{$F(2,97)$} & \multirow[t]{2}{*}{ Contrasts $^{\mathrm{a}}$} \\
\hline & Mean & SD & Mean & SD & Mean & SD & & \\
\hline Basal & 0.66 & 0.13 & 0.72 & 0.24 & 0.78 & 0.26 & $3.28 *$ & $\mathrm{NC}>$ ADHD-C \\
\hline Deltapeak & 0.26 & 0.15 & 0.54 & 0.28 & 0.41 & 0.26 & $13.98 * *$ & ADHD-I, NC > ADHD-C \\
\hline AUCtot & 28.78 & 8.60 & 50.93 & 19.21 & 44.25 & 16.31 & $24.52 * *$ & ADHD-I, NC > ADHD-C \\
\hline AUCnet & -4.71 & 9.56 & 11.77 & 5.69 & 4.25 & 5.71 & $36.40 * *$ & ADHD-I $>$ NC $>$ ADHD-C \\
\hline
\end{tabular}

${ }^{a}$ Bonferroni, $P<0.05 ; * P<0.05 * * P<0.001$

Psychometric characteristics for responders and nonresponders are given in Table 4. To analyze the dichotomous variable "responder, we studied a forward stepwise multiple logistic regression model. The hyperactivity scores on the ADHD rating scale in block 1 turned out to be the best predictor (Wald $=23.42, P<0.001$ ) and this variable alone resulted in $88 \%$ of the children being correctly classified and has a sensitivity of $87 \%$ and a specificity of $91 \%$.

\section{Discussion}

To the best of our knowledge, this is the first report on HPA axis reactivity in prepubertal children with ADHD subtypes as compared with healthy controls.
The reactivity of the HPA axis to stress may have prognostic significance [35]. These findings assist in the speculation that not all patients with ADHD have an underreactivity of the HPA axis, and those that do may have more deficits than the patients with an appropriate reactivity. The present results suggest that hyperactivity and impulsivity in children with ADHD might be associated with dysfunction of the HPA axis. Consistent with our findings, Kaneko et al. [32] demonstrated that abnormal variations in diurnal salivary cortisol were found to be more frequent in severely and moderately hyperactive children with ADHD. More recently, in a population-based study of reactions to a dental examination of children with and without ADHD, indications of a blunted HPA axis response in children with ADHD with high hyperactivity/ impulsivity scores were found [11]. 
Table 4 Psychometric characteristics in responders versus non-responders

\begin{tabular}{|c|c|c|c|c|c|c|}
\hline & \multirow[t]{2}{*}{ Measure } & \multicolumn{2}{|c|}{ Responders $(n=62)$} & \multicolumn{2}{|c|}{ Non-responders $(n=38)$} & \multirow[t]{2}{*}{$t(1,98)$} \\
\hline & & Mean & SD & Mean & SD & \\
\hline \multirow[t]{4}{*}{ AVL } & Total & 21.65 & 12.40 & 48.61 & 14.34 & $9.94 * * *$ \\
\hline & Inattention & 12.08 & 7.21 & 15.05 & 6.04 & $2.22 *$ \\
\hline & Hyperactivity & 4.89 & 3.98 & 16.95 & 6.21 & $10.70 * * *$ \\
\hline & Impulsivity & 4.68 & 4.08 & 16.61 & 6.48 & $10.19 * * *$ \\
\hline \multirow[t]{11}{*}{ CBCL } & Withdrawn & 60.75 & 8.32 & 57.89 & 5.59 & $-2.05^{*}$ \\
\hline & Somatic complaints & 56.48 & 6.77 & 57.97 & 6.91 & 1.07 \\
\hline & Anxious/depressed & 60.64 & 8.29 & 60.43 & 4.98 & -0.16 \\
\hline & Social problems & 57.78 & 7.46 & 58.64 & 4.96 & 0.70 \\
\hline & Thought problems & 56.23 & 7.46 & 60.87 & 8.99 & $2.79 * *$ \\
\hline & Attention problems & 64.08 & 9.77 & 69.71 & 7.14 & $3.32 * *$ \\
\hline & Delinquency & 56.23 & 6.63 & 62.76 & 5.53 & $5.31 * * *$ \\
\hline & Aggression & 56.79 & 7.13 & 62.44 & 4.36 & $4.92 * * *$ \\
\hline & Externalizing score & 54.12 & 10.09 & 61.77 & 6.84 & $4.51 * * *$ \\
\hline & Internalizing score & 58.07 & 9.26 & 59.71 & 5.25 & 1.13 \\
\hline & Total problem score & 56.35 & 10.47 & 61.55 & 6.09 & $3.14 * *$ \\
\hline \multirow[t]{11}{*}{ TRF } & Withdrawn & 57.47 & 7.52 & 55.05 & 8.09 & -1.52 \\
\hline & Somatic complaints & 52.38 & 4.86 & 54.44 & 6.20 & 1.85 \\
\hline & Anxious/depressed & 57.25 & 6.25 & 54.96 & 5.09 & -1.91 \\
\hline & Social problems & 56.87 & 6.94 & 60.47 & 7.59 & $2.43 *$ \\
\hline & Thought problems & 53.78 & 6.98 & 55.81 & 7.88 & 1.34 \\
\hline & Attention problems & 59.65 & 7.53 & 63.66 & 5.28 & $3.13 * *$ \\
\hline & Delinquency & 56.38 & 5.63 & 58.29 & 4.00 & $1.98^{*}$ \\
\hline & Aggression & 57.10 & 5.66 & 60.29 & 4.31 & $3.18 * *$ \\
\hline & Externalizing score & 53.14 & 8.68 & 59.61 & 4.16 & $5.01 * * *$ \\
\hline & Internalizing score & 51.56 & 8.37 & 54.59 & 6.33 & $2.05 *$ \\
\hline & Total problem score & 54.13 & 10.26 & 58.88 & 6.36 & $2.86^{* *}$ \\
\hline
\end{tabular}

* $P<0.05 ; * * P<0.01 ; * * * P<0.001$

Several studies suggest an overall relationship between hyperactivity and DBD, which suggests that hyperactivity may be a risk factor for the further development of DBD $[19,30,49,67,73]$. Although none of our patients met the diagnostic criteria for a comorbid disorder, from a dimensional point of view we found negative correlations between HPA axis reactivity and externalizing problem scores; furthermore, we found positive correlations between HPA axis reactivity and scores for social withdrawal. These findings are consistent with previous studies which suggest that a reduced responsiveness to stress lacks the ability to exhibit age-appropriate inhibition of impulsive and/or aggressive behavior [35, 45, 50, 52, 53, 68, 75]. On the contrary, elevated salivary cortisol levels have been detected in shy and behaviorally inhibited children [61].

In this study, two distinct patient groups with ADHD were identified according to the reactivity of the HPA axis to stress. ADHD-C patients showed a decrease in cortisol reactivity, whereas ADHD-I patients showed an increased cortisol reactivity. As stated by several authors, the ADHDI subtype appears to be a somewhat heterogeneous group $[14,46,48]$. Evidence suggests two distinct dimensions of inattention. The first dimension is the set of inattentive symptoms that can be thought of as primarily reflecting distractibility. The second dimension reflects a quality that is more sluggish, passive, hypoactive, daydreamy, slowmoving, staring, confused, and lethargic in form, and that has been described as sluggish cognitive tempo (SCT). In a study of Carlson and Mann [14] the inattentive-sluggish group received significantly higher teacher ratings on anxiety and depression symptoms than both the inattentivelow sluggish tempo group and the ADHD-C group. Symptoms of SCT are not included in the DSM-IV-TR symptoms of inattention and may be useful in assembling more homogenous groups. An important direction for research is to distinguish subtypes of children with ADHDC, ADHD-I high in SCT, and ADHD-I low in SCT, and to compare these groups on measures of HPA axis reactivity. 
In a recent study by Randazzo et al. [57], the stress response in adolescents with inattentive type ADHD symptoms in both a threshold group with six symptoms and a moderately inattentive group with three symptoms was investigated. Although the sample size was small, they demonstrated that the group at the diagnostic threshold displayed a blunted cortisol response whereas the moderate and comparison groups displayed a normal cortisol stress response.

Some methodological limitations of the present study need to be noted. First, we did not systematically collect information on the occurrence of significant early life events in our children. We can therefore only speculate about the possible mechanisms underlying our findings. Early adverse experiences, including neglect or abuse, can have permanent effects on the developing neurobiological systems in the brain, including the HPA axis [12]. Second, the study cannot clarify whether a pattern of underreactivity in ADHD-C children is the cause or the consequence of the problem behavior. Only longitudinal studies can resolve the issue of the direction of causality. Third, there is a possibility that the subtypes may change during development; some children shifted to another subtype, whereas others desisted from ADHD in later years [40]. We tried to compensate for this by a narrow limitation of the age range. Fourth, no subjects with ADHD-H could be included in this study, so that one can only speculate on HPA axis reactivity in this subtype. The inclusion of ADHD-H subtypes is a desideratum for future research. Fifth, the absence of comorbid mood disorders has implications for generalizability of our findings.

In conclusion, the present findings suggest that patients with ADHD-C are characterized by low-cortisol responsivity to psychosocial stress. Our findings could contribute to the ongoing debate on the possibility that ADHD-C and ADHD-I could be qualitatively distinct and unrelated disorders. The emphasis on ADHD-I as an independent entity could lead to the formulation of new theories concerning this disorder. The currently leading psychological theories on ADHD focus on response inhibition deficit [74], a deviant motivational attitude [44], or an energetical state dysregulation [65], thereby emphasizing the construct of impulsiveness which is only accounted for by ADHD-C and ADHD-H.

The current findings warrant further research on the biological mechanisms that regulate the reaction to psychosocial stress and activation of the HPA axis in ADHD subtypes. Future research should aim to investigate HPA (re)activity at different levels of the axis (hypothalamus, pituitary and adrenals) and at higher levels (e.g., the amygdala and limbic system) simultaneously to elucidate the neuroendocrinological mechanisms underlying the observed HPA axis dysfunction in ADHD populations.
Moreover, new strategies for investigating psychoneuroendocrinological systems should be developed, in combination with both structural and functional imaging techniques, as well as molecular genetic studies to provide a better understanding of both the (neuro) biological and psychosocial mechanisms involved in the development of ADHD.

Acknowledgments This work has been supported by the Special Research Fund of the University of Antwerp. Stephan Claes is a Senior Clinical Investigator of the Fund for Scientific Research Flanders. We are grateful to all the children and their parents for their cooperation and participation in this research study. We acknowledge J. Sulon of the Department of Reproduction Physiology of the University of Liège for the analyses of salivary cortisol. We also acknowledge W. Ang, M. Coudeville, H. De Vlieger, I. Jespers, W. Mengde, I. Mussche, P. Nordin, K. Ponnet, S. Sliwinski, A. Steppe, and E. Van den haute for their contributions.

Conflict of interest statement The authors reported no biomedical financial interest or potential conflicts of interest.

\section{References}

1. Aardal E, Holm AC (1995) Cortisol in saliva : reference ranges and relation to cortisol in serum. Eur J Clin Chem Clin Biochem 33:927-932

2. Achenbach TM (1991a) Manual for the child behavior checklist and 1991 profile. Department of Psychiatry, University of Vermont, Burlington

3. Achenbach TM (1991b) Manual for the teacher's report form and 1991 profile. Department of Psychiatry, University of Vermont, Burlington

4. American Psychiatric Association (APA) (2000) Diagnostic and statistical manual of mental disorders, text revision, 4th edn. American Psychiatric Press, Washington

5. Barkley RA, DuPaul GJ, McMurray MB (1990) Comprehensive evaluation of attention deficit disorder with and without hyperactivity as defined by research criteria. J Consult Clin Psychol 58:775-789

6. Barkley RA (1997) Behavioral inhibition, sustained attention and executive functions: constructing a unifying theory of ADHD. Psychol Bull 121:65-94

7. Barkley RA (2001) The inattentive type of ADHD as a distinct disorder: what remain to be done. Clin Psychol Sci Pract 8:489493

8. Biederman J, Faraone SV (2005) Attention-deficit hyperactivity disorder. Lancet 366:237-248

9. Biederman J (2005) Attention-deficit/hyperactivity disorder: a selective overview. Biol Psychiatry 57:1215-1220

10. Biederman J, Faraone SV (2006) The effects of attention-deficit/ hyperactivity disorder on employment and household income. MedgenMed 18:12

11. Blomqvist M, Holmberg K, Lindblad F, Fernell E, Ek U, Dahllöf G (2007) Salivary cortisol levels and dental anxiety in children with attention deficit hyperactivity disorder. Eur J Oral Sci 115:1-6

12. Carlson M, Earls F (1997) Psychological and neuroendocrinological sequelae of early social deprivation in institutionalized children in Romania. Ann N Y Acad Sci 807:419-428

13. Carlson CL, Shin M, Booth J (1999) The case for DSM-IV subtypes in ADHD. Ment Retard Dev Disabil Res Rev 5:199-206 
14. Carlson CL, Mann M (2002) Sluggish cognitive tempo predicts a different pattern of impairment in the attention deficit hyperactivity disorder, predominantly inattentive type. J Clin Child Adolesc Psychol 31:123-129

15. Cohen J (1992) A power primer. Psychol Bull 112:155-159

16. Diamond A (2005) Attention-deficit disorder (attention-deficit/ hyperactivity disorder without hyperactivity): a neurobiologically and behaviourally distinct disorder from attention-deficit/hyperactivity disorder (with hyperactivity). Dev Psychopathol 17:807825

17. Dickerson SS, Kemeny ME (2004) Acute stressors and cortisol responses: a theoretical integration and synthesis of laboratory research. Psychol Bull 130:355-391

18. Eiraldi RB, Power TJ, Nezu CM (1997) Patterns of comorbidity associated with subtypes of attention-deficit/hyperactivity disorder among 6- to 12-year old children. J Am Acad Child Adolesc Psychiatry 36:503-514

19. Faraone SV, Biederman J, Weber W, Russell RL (1998) Psychiatric, neuropsychological and psychosocial features of DSMIV subtypes of attention-deficit/hyperactivity disorder: results from a clinically referred sample. J Am Acad Child Adolesc Psychiatry 37:185-193

20. Farrington DP (1993) Childhood origins of teenage antisocial behavior and adult social dysfunction. J R Soc Med 86:13-17

21. Frick PJ (2001) Effective interventions for children and adolescents with conduct disorder. Can J Psychiatry 46:597-608

22. Gadow KD, Drabick DA, Loney J, Sprafkin J, Salisbury H, Azizian A, Schwartz J (2004) Comparison of ADHD-symptom subtypes as source-specific syndromes. J Abnorm Child Psychol 45:1135-1149

23. Gray JA (1982) The neuropsychology of anxiety: an enquiry into the function of the septo-hippocampal system. Oxford University Press, New York

24. Gray JA (1985) Issues in the neuropsychology of anxiety. In: Tuma AH, De Maser JD (eds) Anxiety and the anxiety disorders. Lawrence Erlbaum, Hillsdale, pp 5-25

25. Gray JA (1987) The psychology of fear and stress, 2nd edn. Cambridge University Press, Cambridge

26. Gray JA (1991) Neural systems, emotions and personality. In: Madden $\mathbf{J}$ (ed) Neurobiology of learning, emotion and affect. Raven Press, New York, pp 273-306

27. Hankin BL, Abramson LY, Moffitt TE, Silva PA, McGee R, Angell KE (1998) Development of depression from preadolescence to young adulthood: emerging gender differences in a 10-year longitudinal study. J Abnorm Psychol 107:128-140

28. Hollingshead AB (1975) Four factor index of social status. Department of Sociology, Yale University, New Haven

29. Hong HJ, Shin DW, Lee EH, Oh YH, Noh KS (2003) Hypothalamic-pituitary-adrenal reactivity in boys with attention deficit hyperactivity disorder. Yonsei Med J 44:608-614

30. Ishii T, Takahashi O, Kawamura Y, Ohta T (2003) Comorbidity in attention deficit-hyperactivity disorder. Psychiatry Clin Neurosci 57:457-463

31. Kadesjö B, Gillberg C (2001) The comorbidity of ADHD in the general population of Swedish school-age children. J Child Psychol Psychiatry 42:487-492

32. Kaneko M, Hoshino $\mathrm{Y}$, Hashimoto S, Okano T, Kumashiro H (1993) Hypothalamic-pituitary-adrenal axis function in children with attention-deficit hyperactivity disorder. J Autism Dev Disord 23:59-65

33. Kariyawasam SH, Zaw F, Handley SL (2002) Reduced salivary cortisol in children with comorbid attention deficit hyperactivity disorder and oppositional defiant disorder. Neuroendocrinol Lett 23:45-48

34. Kaufman J, Birmaher B, Brent D, Rao U, Flynn C, Moreci P, Williamson D, Ryan N (1997) Schedule for affective disorders and schizophrenia for school-aged children — present and lifetime version (K-SADS-PL): initial reliability and validity data. J Am Acad Child Adolesc Psychiatry 35:980-988

35. King JA, Barkley RA, Barrett S (1998) Attention-deficit hyperactivity disorder and the stress response. Biol Psychiatry 44:72-74

36. Kirschbaum C, Pirke KM, Hellhammer DH (1993) The trier social stress test: a tool for investigating psychobiological stress responses in a laboratory setting. Neuropsychobiology 28:76-81

37. Kirschbaum C, Hellhammer DH (1994) Salivary cortisol in psychoendocrine research: recent developments and applications. Psychoneuroendocrinology 19:313-333

38. Kudielka BM, Buske-Kirschbaum A, Hellhammer DH, Kirschbaum C (2004) HPA axis responses to laboratory stress in healthy elderly adults, younger adults, and children: impact of age and gender. Psychoneuroendocrinology 29:83-98

39. Lahey BB, Loeber R, Quay HC, Frick PJ, Grimm J (1992) Oppositional defiant and conduct disorders: issues to be resolved for DSM-IV. J Am Acad Child Adolesc Psychiatry 31:539-546

40. Lahey BB, Pelham WE, Loney J, Lee SS, Wilcutt E (2005) Instability of the DSM-IV subtypes of ADHD from preschool through elementary school. Arch Gen Psychiatry 62:896-902

41. Loeber R, Green SM, Keenan K, Lahey BB (1995) Which boys will fare worse ? Early predictors of the onset of conduct disorder in a 6-year longitudinal study. J Am Acad Child Adolesc Psychiatry 34:499-509

42. Lupien SJ, King S, Meaney MJ, McEwen BS (2000) Child's stress hormone levels correlate with mother's socioeconomic status and depressive state. Biol Psychiatry 48:976-980

43. Marshall WA, Tanner JM (1969) Variations in the pattern of pubertal changes in girls. Arch Dis Child 44:291

44. Marshall RW, Hynd GW, Handwerk MJ, Hall J (1997) Academic underachievement in ADHD subtypes. J Learn Disabil 30:635642

45. McBurnett K, Lahey BB, Rathouz PJ, Loeber R (2000) Low salivary cortisol and persistent aggression in boys referred for disruptive behavior. Arch Gen Psychiatry 57:38-43

46. McBurnett K, Pfiffner LJ, Frick PJ (2001) Symptom properties as a function of ADHD type: an argument for continued study of sluggish cognitive tempo. J Abnorm Child Psychol 29:207-213

47. McGee R, Feehan M, Williams S, Anderson J (1992) DSM-III disorders from age 11 to age 15 years. J Am Acad Child Adolesc Psychiatry 31:50-59

48. Milich R, Balentine AC, Lynam DR (2001) ADHD combined type and ADHD predominantly inattentive type are distinct and unrelated disorders. Clin Psychol Sci Pract 8:463-488

49. Morgan AE, Hynd GW, Riccio CA, Hall J (1996) Validity of DSM-IV ADHD predominantly inattentive and combined types: relationship to previous DSM diagnoses/subtype differences. J Am Acad Child Adolesc Psychiatry 35:325-333

50. Moss HB, Vanyukov M, Yao JK, Kirillova GP (1999) Salivary cortisol responses in prepubertal boys: the effects of parental substance abuse and association with drug use behavior during adolescence. Biol Psychiatry 45:1293-1299

51. Oosterlaan J, Sergeant JA (1998) Response inhibition and response re-engagement in attention-deficit/hyperactivity disorder, disruptive, anxious and normal children. Behav Brain Res 94:33-43

52. Oosterlaan J, Geurts HM, Knol DL, Sergeant JA (2005) Low basal salivary cortisol is associated with teacher-reported symptoms of conduct disorder. Psychiatry Res 134:1-10

53. Popma A, Jansen LM, Vermeiren R, Steiner H, Raine A, Van Goozen SH, van Engeland H, Doreleijers TA (2006) Hypothalamus pituitary adrenal axis and autonomic activity during stress in delinquent male adolescents and controls. Psychoneuroendocrinology 31:948-957 
54. Power TJ, Costigan TE, Eiraldi RB, Leff SS (2004) Variations in anxiety and depression as a function of ADHD subtypes defined by DSM-IV: do subtype differences exist or not? J Abnorm Child Psychol 32:27-37

55. Pruessner JC, Kirschbaum C, Meinlschmid G, Hellhammer DH (2003) Two formulas for computation of the area under the curve represent measures of total hormone concentration versus timedependent change. Psychoneuroendocrinology 28:916-931

56. Quay HC (1997) Inhibition and attention deficit hyperactivity disorder. J Abnorm Psychol 25:7-13

57. Randazzo WT, Dockray S, Susman EJ (2008) The stress response in adolescents with inattentive type ADHD symptoms. Child Psychiatry Hum Dev 39:27-38

58. Reichart CG, Wals M, Hillegers M (2000) Vertaling K-SADS. H.C. Rümke Groep, Utrecht

59. Ryan ND (1998) Psychoneuroendocrinology of children and adolescents. Psychiatr Clin North Am 21:435-441

60. Schachar RJ, Tannock R, Logan G (1993) Inhibitory, control, impulsiveness, and attention deficit hyperactivity disorder. Clin Psychol Rev 13:721-739

61. Schmidt LA, Fox NA, Rubin KH, Sternberg EM, Gold PW, Smith CC (1997) Behavioral and neuroendocrine responses in shy children. Dev Psychobiol 30:127-140

62. Scholte EM, van der Ploeg JD (1998) Handleiding ADHDvragenlijst (AVL). Swets Test Publishers, Lisse

63. Schulz KP, Halperin JM, Newcorn JH, Sharma V, Gabriel S (1997) Plasma cortisol and aggression in Boys with ADHD. J Am Acad Child Adolesc Psychiatry 36:605-609

64. Sondeijker FE, Ferdinand RF, Oldehinkel AJ, Veenstra R, Tiemeier H, Ormel J, Verhulst FC (2007) Disruptive behaviors and HPA-axis activity in young adolescent boys and girls from the general population. J Psychiatr Res 41:570-578

65. Sonuga-Barke EJS (2002) Psychological heterogeneity in AD/ HD—a dual pathway model of Behaviour and cognition. Behav Brain Res 130:29-36
66. Sulon J, Demey-Ponsart L, Beauduin P, Sodoyez JC (1978) Radioimmunoassay of corticosterone, cortisol and cortisone: their application to human cord and maternal plasma. J Steroid Biochem 9:671-676

67. Takahashi K, Miyawaki D, Suzuki F, Mamoto A, Matsushima N, Tsuji H, Horino A, Ballas PA, Kiriike N (2007) Hyperactivity and comorbidity in Japanese children with attention-deficit/ hyperactivity disorder. Psychiatry Clin Neurosci 61:255-262

68. Van Goozen SH, Matthys W, Cohen-Kettenis PT, Gispen-de Wied C, Wiegant VM, van Engeland H (1998) Salivary cortisol and cardiovascular activity during stress in oppositional-defiant disorder boys and normal controls. Biol Psychiatry 43:531-539

69. van West D, Claes S, Sulon J, Deboutte D (2008) HPA reactivity in prepubertal children with social phobia. J Affect Disord 111:281-290

70. Verhulst FC, Van der Ende J (1993) "Comorbidity" in an epidemiological sample: a longitudinal perspective. J Child Psychol Psychiatry 34:767-783

71. Vila G, Zipper E, Dabbas M, Bertrand C, Robert JJ, Ricour C, Mouren-Simeoni MC (2004) Mental disorders in obese children and adolescents. Psychosom Med 66:387-394

72. Wechsler D (1974) Wechsler intelligence scale for childrenrevised. Psychological Corporation, New York

73. Weiss M, Worling D, Wasdell M (2003) A chart review study of the inattentive and combined types of ADHD. J Atten Disord 7:1-9

74. Welsh MC, Pennington BF, Groisser DB (1988) A normativedevelopmental study of executive functioning: a window on prefrontal function in children. Dev Neuropsychol 7:131-149

75. Yang SJ, Shin DW, Noh KS, Stein MA (2007) Cortisol is inversely correlated with aggression for those boys with attention deficit hyperactivity disorder who retain their reactivity to stress. Psychiatry Res 153:55-60 